\title{
PENGARUH LIABILITAS DAN EKUITAS TERHADAP PROFITABILITAS PADA PT. PRIMARINDO ASIA INFRASTRUCTURE TBK
}

\author{
Safira Nurlita ${ }^{1}$, Aliah Pratiwi ${ }^{2}$ \\ ${ }^{1,2}$ Sekolah Tinggi Ilmu Ekonomi (STIE) Bima \\ Email : Safiranurlita16.stiebima@gmail.com ${ }^{1}$, aliahpratiwi@ymail.com²
}

\begin{abstract}
This study aims to determine the effect of liabilities and equity on profitability. Indicators to measure profitability use Return on Equity (ROE), while liabilities use the ratio of short-term debt to equity (STDE) and shareholder equity using the ratio of prorietary ratio $(P R)$. this research was conducted at PT. Primarindo Asia infrastructure, tbk. This type of research is associative research. The sampling technique used is a non probability sampling technique that is purposive sampling, with the sample used is for 8 years. The analysis technique used in this study is the classic assumption test and multiple regression analysis. Based on the results of the regression analysis shows short-term liabilities, and capital alone has no influence on profitability either partially or simultaneously.
\end{abstract}

Keywords: Short-Term Debt (STDE), Prorietary Ratio (PR) and Return on Equity (ROE).

\section{Pendahuluan}

Seiring perkembangan jaman perusahaan manufkatur terus mengalami perkembangan dengan terus menggunakan teknologi terbaru dalam menunjang bisnis mereka. Perusahaan manufaktur merupakan penunjang bagi perekonomian dunia karena perusahaan manufaktur memiliki keunggulan tersendiri dibanding sektor lain. Pada umumnya perusahaan didirikan agar memperoleh profit atau laba yang tinggi agar kelangsungaan hidup perusahan terjamin.

Prihadi (2010:138-139) menyebutkan profitabilitas adalah kemapuan perusahaan dalam menghasilkan laba. Semakin tinggi profitabilitas sebuah perusahaan maka semakin bagus kinerja dari perusahaan tersebut, perusahaan yang memiliki tingkat profitabilitas yang tinggi akan sangat baik bagi perusahaan. Profitabilitas suatu perusahaan di pengaruhi oleh berbagai faktor salah satunya di pengaruhi oleh utang jangka pendek. Utang jangka pendek merupakan utang yang jatuh temponya dalam 1tahun periode, dimana utang jangka pendek ini memiliki bunga yang lebih rendah dari utang jangka panjang yang bisa meningkatkan profitabilitas suatu perusahaan. Semakin banyak tambahan utang untuk investasi akan menaikan ROE perusahaan ${ }^{\mathrm{ii}}$. (Sudana, 2015:181).

Ekuitas merupakan modal sendiri yang terus ditingkatkan kesehatannya, terutama untuk memantapkan struktur modal perusahaan. Modal sendiri merupakan modal yang berasal dari dalam perusahaan. Perusahaan yang memperoleh laba akan menghasilkan kas dari dalam perusahaan sehingga mengurangi kebutuhan dana yang berasal dari luar perusahaan karena perusahaan mampu meningkatkan profitabilitasnya. 
PT. Primarindo Asia Infrastructure Tbk merupakan perusahaan manufaktur yang bergerak di bidang industri alas kaki. Perusahaan ini selalu melakukan berbagai upaya untuk meningkatkan kinerja perusahaan guna mendapatkan profit yang baik.

Tabel 1 Data Liabilitas, Ekuitas dan Laba PT. Primarindo Asia Infrastructure, Tbk Tahun 2013 - 2018 (dalam satuan rupiah)

\begin{tabular}{|c|c|c|c|}
\hline Tahun & Liabilitas & Ekuitas & Laba \\
\hline $\mathbf{2 0 1 5}$ & 301.570 .909 .687 & -202.012 .514 .927 & 21.828 .914 .738 \\
\hline $\mathbf{2 0 1 6}$ & 189.216 .746 .183 & -97.175 .471 .622 & 25.117 .618 .621 \\
\hline $\mathbf{2 0 1 7}$ & 173.964 .702 .574 & -84.637 .373 .721 & 17.254 .663 .996 \\
\hline $\mathbf{2 0 1 8}$ & 179.038 .284 .760 & -80.847 .643 .921 & 16.758 .353 .102 \\
\hline
\end{tabular}

(sumber : Annual Report PT. primarindo Asia Infrastructure, Tbk.)

Berdasarkan tabel diatas dapat dilihat bahwa ekuitas pada PT. Primarindo Asia Infrastructure bernilai negatif hal ini dikarenakan perusahaan lebih memililih untuk menggunakan dana eksternal daripada dana internal untuk melakukan kegiatan operasional perusahaan. Tidak hanya itu, laba perusahaan juga mengalami fluktuasi pada tahun 2015 laba usaha sebesar Rp. 21,82 milyar, kemudian pada tahun 2016 laba usaha mengalami peningkatan sebesar Rp. 25,11 milyar. Peningkatan laba usaha karena perusahaan menjual asetnya berupa tanah. Selain itu laba usaha perusahaan mengalami penurunan seiring dengan penurunan total penjualan. Kemudian pada tahun 2017 laba usaha mengalami penurunan yaitu sebesar Rp. 17,25 milyar. Penurunan ini disebabkan oleh menurunnya penjualan, hingga 2018 laba usaha makin menurun, penurunannya sebesar Rp. 16,75 milyar. Penurunan ini juga disebabkan oleh menurunnya pendapatan dari penjualan, yang antara lain disebabkan oleh lemahnya daya beli masyarakat serta persaingan usaha termasuk dari produk impor yang lebih murah.

Dari uaraian masalah diatas mendorong peneliti untuk melakukan penelitian guna untuk mengetahui dan membuktikan seperti apa "pengaruh liabilitas dan ekuitas pada PT. Primarindo Asia infrastructure, tbk. Berdasarkan uraian diatas maka rumusan masalah dalam penelitian ini adalah: pertama, apakah terdapat pengaruh yang signifikan secara parsial liabilitas jangka pendek terhadap profitabilitas pada PT. primarindo Asia Infrastructure tbk? kedua, apakah terdapat pengaruh yang signifikan secara parsial modal sendiri terhadap profitabilitas pada PT. Primarindo Asia Infrastructure tbk ? ketiga, apakah terdapat pengaruh yang signifikan secara simultan liabilitas jangka pendek dan modal sendiri terhadap profitabilitas pada PT. Primarindo asia infrastructure Tbk ?. Penelitian ini bertujuan untuk mengetahui pengaruh yang signifikan secara parsial dan simultan liabilitas jangka pendek, dan modal sendiri terhadap profitabilitas pada PT. Primarindo Asia Infrastructure tbk.

\section{Tinjauan Pustaka}

\section{Liabilitas}

Menurut Irton (2009). kewajiban (liabilities) merupakan hutang perusahaan masa kini yang timbul dari peristiwa masa lalu, penyelesaiannya diharapkan mengakibatkan arus keluar dari sumber daya perusahaan yang mengandung maanfaat ekonomi ${ }^{\text {iii }}$. Samryn (2014:39) kewajiban merupakan kelompok utang yang masih harus dilunasi kepada pihak ketiga ${ }^{\text {iv }}$. 
Kewajiban atau utang dapat diklasifikasikan menjadi dua jenis yaitu :

a. Utang jangka pendek

Rudianto (2012:47) menyebutkan utang jangka pendek merupakan utang yang memiliki waktu jatuh tempo kurang dari satu periode akutansi atau satu tahun sejak disusunnya laporan keuangan perusahaan ${ }^{v}$. Sudana (2015:203) menjelaskan bahwa utang jangka pendek memiliki cost of capital atau bunga yang lebih rendah daripada utang jangka panjang ${ }^{\mathrm{vi}}$. Pengukuran utang jangka pendek pada penelitian ini menggunakan rumus short therm debt to total equity

b. Utang jangka panjang

Rudianto (2012:277) utang jangka panjang merupakan utang yang jatuh temponya lebih dari satu periode akutansi. Utang jangka Panjang biasanya timbul karena adanya kebutuhan dana untuk pembelanjaan investasi jangka Panjang dan bersifat permanen seperti asset tetap dan menaikan jumlah modal permanen ${ }^{\text {vii }}$. Pengukuran utang jangka Panjang pada penelitian ini menggunakan rumus long term debt to total equity

2. Modal sendiri

Riyanto (2015:240) menyebutkan modal sendiri merupakan modal yang berasal dari dalam perusahaan yang terdiri tiga sumber utama yaitu modal saham, cadangan dan keuntungan. Modal tersebut terdiri atas saham biasa, saham preferen, akumulasi laba

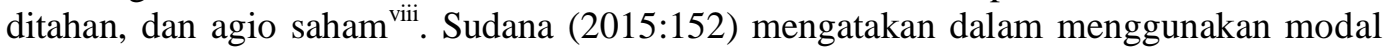
sendiri perusahaan harus mengeluarkan biaya dala menggunakan modal atau cost of capital atas dana yang diperoleh sebagai pendapatan mínimum yang diisyaratkan oleh pemilik modal ${ }^{\text {ix }}$. Pengukuran modal sendiri pada penelitian ini menggunakan rumus proriety ratio.

3. Profitabilitas

Menurut brigham dan houston (2006:107) rasio profitabilitas adalah rasio yang digunakan untuk mengetahui kemampuan perusahaan dalam menghasilkan laba atau seberapa efektif pengelolaan perusahaan oleh manajemen. ${ }^{\mathrm{x}}$ Menurut kasmir (2008:196), rasio profitabilitas merupakan rasio untuk menilai kemampuan perusahaan dalam mencari keuntungan ${ }^{\mathrm{xi}}$.

Jenis-jenis rasio profitabilitas menurut (kasmir, 2008:196):

1. Net Profit Margin (NPM)

2. Return on Asset (ROA)

3. Earning per Share (EPS)

4. Return on Equity (ROE)

5. Gross Profit Margin (GPM)

6. Return On Investment (ROI)

Rasio yang digunakan dalam penelitian ini yaitu Return on Equity (ROE) merupakan rasio yang digunakan untuk mengukur laba bersih setelah pajak dengan modal sendiri.

4. Pengaruh liabilitas jangka pendek terhadap profitabilitas

Penelitian Prasetyo (2017) menjelaskan bahwa utang jangka pendek berpengaruh positif dan signifikan terhadap profitabilitas pada perusahaan property dan real estate selama tahun penelitian. Hubungan positif tersebut menunjukan bahwa semakin besar nilai rasio hutang jangka pendek pada perusahaan property dan real estate akan meningkatkan profitabilitas dan sebaliknya

$\mathrm{H} 1=$ Utang jangka pendek berpengaruh positif terhadap profitabilitas.

5. Pengaruh modal sendiri terhadap profitabilitas

Penelitian Prasetyo (2017) menjelaskan bahwa modal sendiri berpengaruh positif dan signifikan terhadap profitabilitas. Hubungan positif tersebut menunjukan bahwa semakin besar nilai rasio modal sendiri pada perusahaan property dan real estate akan meningkatkan profitabilitas dan sebaliknya.

$\mathrm{H} 2=$ Modal sendiri berpengaruh positif terhadap profitabilitas . 
6. Pengaruh liabilitas jangka pendek dan modal sendiri terhadap profitabilitas

Penelitian silitonga dan ginting (2019) menjelaskan bahwa pendanaan dari luar dan modal sendiri berpengaruh signifikan terhadap profitabilitas pada perusahaan property dan real estate yang terdaftar di bursa efek indonesia.

H3 = liabilitas jangka pendek dan modal sendiri berpengaruh terhadap profitabilitas.

\section{Hasil dan Pembahasan}

Berdasarkan hasil pengolahan data yang dilakukan diperoleh hasil bahwa liabilitas jangka pendek, dan modal sendiri sama-sama tidak berpengaruh terhadap profitabilitas

Berikut adalah hasil pengujian statistik yang dilakukan dalam penelitian ini :

\section{Hasil uji asumsi klasik}

Penelitian ini telah melewati Uji asumsi klasik yaitu Uji normalitas, Uji multikolinearitas, Uji heteroksedasitas, dan Uji auto korelasi.

\section{Uji mormalitas}

Uji normalitas pada penelitian ini menggunakan uji one sample kolmogrovsminorv (K-S) dan di dapatkan hasil asymp sig (2-tailed) sebesar 0,930 Hal ini menandakan bahwasannya data tersebut berdistribusi normal karena 0,930 >0,05.

\section{Uji multikolinearitas}

Uji multikolinearitas dalam penelitian ini menggunakan hasil yang didapatkan dari nilai tolerance dan VIF. Besarnya nilai tolerance pada penelitian ini sebesar 0,312 berada diatas 0,1 dan nilai VIF pada penelitian ini yaitu sebesar 3,201 kurang dari 10 itu artinya tidak terjadi multikolinearitas dalam regresi.

\section{Uji heteroksedisitas}

Uji heteroksedisitas dalam penelitian menggunaka uji glejser dan dalam penelitian ini tidak terjadi gejala heteroksedisitas. Nilai signifikan pada tiap variabel independen menunjukan hasil lebih dari 0,05. Nilai signifikan untuk variabel liabilitas jangka pendek (X1) yaitu $0,127<0,05$ dan nilai signifikan modal sendiri yaitu $0,55<0,05$ sehingga kesimpulan yang dapat diambil adalah tidak adanya gejala heteroksedisitas dalam model regresi ini.

\section{Uji autokorelasi}

Uji autokorelasi menggunakan uji run test. Berdasarkan hasil output spps, didapatkan nilai asymp.sig (2-tailed) sebesar 0,252 lebih besar dari >0,05 sehibngga kesimpulan yang dapat diambil adalah tidak terdapat gejala atau masalah autokorelasi. 


\section{Hasil analisis regresi linear berganda Persamaan regresi}

Tabel 2 Coefficients

Coefficients ${ }^{\mathrm{a}}$

\begin{tabular}{|c|c|c|c|c|c|}
\hline \multirow[b]{2}{*}{ Model } & \multicolumn{2}{|c|}{ Unstandardized Coefficients } & \multirow{2}{*}{$\begin{array}{c}\begin{array}{c}\text { Standardized } \\
\text { Coefficients }\end{array} \\
\text { Beta }\end{array}$} & \multirow[b]{2}{*}{$\mathrm{T}$} & \multirow[b]{2}{*}{ Sig. } \\
\hline & B & Std. Error & & & \\
\hline 1 (Constant) & -.039 & .278 & & -.140 & .894 \\
\hline STDE & .126 & .192 & .378 & .658 & .540 \\
\hline PR & -.056 & .092 & -.351 & -.611 & .568 \\
\hline
\end{tabular}

a. Dependent Variable: ROE

Berdasarkan hasil dari tabel 2, persamaan regresi adalah :

$\mathrm{Y}=\mathrm{a}+\mathrm{bX}+\mathrm{X}_{1}+\mathrm{X}_{2}$

$\mathrm{Y}=-0,039+0,126 \mathrm{X}_{1}-0,056 \mathrm{X}_{2}$

- $\quad$ Nilai Konstanta $(a)=-0,039$ menunjukkan jika nilai liabilitas jangka pendek $\left(\mathrm{X}_{1}\right)$ dan modal sendiri $\left(\mathrm{X}_{2}\right)$ memiliki nilai nol $(0)$ maka ROE $(\mathrm{Y})$ akan turun sebesar 0,039 .

- $\quad$ Nilai koefisien liabilitas jangka pendek $\left(X_{1}\right)$ untuk variabel $X_{1}$ sebesar 0,126 . artinya jika utang jangka panjang naik sebesar Rp 1 dimana modal sendiri konstan maka profitabilitas pada PT. primarindo Asia Infrastructure, Tbk akan naik sebesar 0,126.

- Nilai koefisien modal sendiri $\left(\mathrm{X}_{2}\right)$ untuk variabel $\mathrm{X}_{2}$ sebesar -0,056, menunjukkan bahwa modal sendiri mempunyai hubungan yang berlawanan arah. artinya bahwa setiap kenaikan modal sendiri $\left(\mathrm{X}_{1}\right)$ satu satuan maka variabel ROE $(\mathrm{Y})$ akan turun sebesar 0,056 .

\section{Koefisien korelasi \& determinasi}

\section{Tabel 3 Model Summary}

Model Summary

\begin{tabular}{|l|c|r|r|c|}
\hline Model & $\mathrm{R}$ & R Square & \multicolumn{1}{c|}{$\begin{array}{c}\text { Adjusted R } \\
\text { Square }\end{array}$} & $\begin{array}{c}\text { Std. Error of the } \\
\text { Estimate }\end{array}$ \\
\hline 1 & $.697^{\mathrm{a}}$ & .485 & .280 & .07069 \\
\hline
\end{tabular}

a. Predictors: (Constant), PR, STDE

\section{Koefisien korelasi}

Berdasarkan hasil olah data SPSS nilai koefisien korelasi yaitu sebesar 0,697. Artinya tingkat keeratan hubungan antara liabilitas jangka pendek dan modal sendiri terhadap profitabilitas pada PT. primarindo Asia Infrastructure, Tbk kuat yaitu sebesar 0,697

\section{Koefisien determinasi}

Berdasarkan hasil olah data SPSS nilai koefisien determinasi yaitu sebesar 0,458. Artinya kontribusi pengaruh antara liabilitas jangka pendek dan modal sendiri terhadap profitabilitas pada PT. primarindo Asia Infrastructure, Tbk yaitu sebesar 45,48\% sedangkan sisanya 54,2\% dipengaruhi oleh variabel lain yang tidak diteliti dalam penelitian ini. 
ANOVA $^{b}$

\begin{tabular}{|l|r|r|r|l|l|}
\hline Model & Sum of Squares & Df & Mean Square & F & \multicolumn{1}{c|}{ Sig. } \\
\hline $1 \quad$ Regression & .024 & 2 & .012 & 2.358 & $.190^{\mathrm{a}}$ \\
Residual & .025 & 5 & .005 & & \\
Total & .049 & 7 & & & \\
\hline
\end{tabular}

erdasarkan tabel diatas nilai sig uji $\mathrm{F}$ adalah sebesar $0,190>0,05$. Ini menandakan bahwasanya secara bersamaan liabilitas jangka pendek, dan modal sendiri tidak berpengaruh terhadap profitabilitas.

\section{Hasil uji statistik t}

Berdasarkan hasil uji statistik $\mathrm{t}$ yang ditunjukan pada tabel 2 Maka dapat disimpulkan sebagai berikut:

\section{Liabilitas jangka pendek tidak berpengaruh terhadap profitabilitas}

Uji signifikasi t menunjukan nilai signifikasi sebesar 0,540 lebih besar dari 0,05, dan nilai thitung sebesar 0,658 dan Nilai t-hitung untuk variabel utang jangka pendek (X1) adalah sebesar 0,658. Pengujian dua arah $\alpha / 2=0,05 / 2=0,025$ dan derajat bebas $(\mathrm{dk})=\mathrm{n}-\mathrm{k}$ dengan $\mathrm{k}$ adalah jumlah variabel bebas dan terikat, maka $(\mathrm{dk})=8-3=5$. Sehingga diperoleh nilai t-tabel sebesar 2,571. Nilai t-hitung < dari nilai t-tabel Ho diterima dan Ha ditolak, Dengan demikian, dapat dikatakan utang jangka pendek tidak berpengaruh secara signifikan terhadap profitabilitas.

\section{Modal sendiri tidak berpengaruh terhadap proftabilitas}

Uji signifikasi t menunjukan nilai signifikasi sebesar 0,130 lebih besar dari 0,05. Nilai t-hitung untuk variabel modal sendiri (X3) adalah sebesar -1,172 Pengujian dua arah $\alpha / 2=0,05 / 2=0,025$ dan derajat bebas $(\mathrm{dk})=\mathrm{n}-\mathrm{k}$ dengan $\mathrm{k}$ adalah jumlah variabel bebas dan terikat, maka $(\mathrm{dk})=8-4=4$ Sehingga diperoleh nilai $\mathrm{t}$-tabel sebesar 2,776 . Nilai $\mathrm{t}$ hitung < dari nilai t-tabel Ho diterima dan Ha ditolak, dengan demikian dapat dikatakan modal sendiri tidak memiliki pengaruh terhadap profitabilitas.

\section{Pengaruh liabilitas jangka pendek terhadap profitabilitas}

Uji signifikasi parsial (uji t) menunjukan bahwa nilai signifikasi pada variabel liabilitas jangka pendek adalah lebih besar daripada tingkat level of significant. Sehingga dapat dikatakan variabel liabilitas jangka pendek tidak memiliki pengaruh terhadap profitabilitas pada PT. Primarindo Asia Infrastruucture, Tbk selama tahun penelitian. Utang jangka pendek dapat meningkatkan profitabilitas dengan bunganya yang kecil, beban bunga yang kecil ini nantinya akan meningkatkan laba perusahaan dan berdampak pada tingginya tingkat profitabilitas yang didapatkan perusahaan. Namun pada penelitian ini dinyatakan bahwasannya liabilitas tidak terlalu mempengaruhi profitabilitas perusahaan, dapat dilihat dari hasil penelitian yang tidak signifikan. Hal ini dikarenakan bahwa utang jangka pendek juga memiliki resiko bagi suatu perusahaan. Utang jangka pendek memiliki biaya bunga yang relative berfluktuasi, perusahaan terlalu banyak menggunakan hutang jangka pendek hal ini dapat menyebabkan kesulitan likuiditas yang akan berdampak pada kebangkrutan. Likuiditas hutang jangka pendek lebih buruk dibanding hutang jangka panjang. penelitian sesuai dengan penelitian sebelumnya yaitu penelitian yang dilakukan L ayu (2013) yang meneliti tentang analisis pengaruh 
penggunaan dana dari luar perusahaan dan modal sendiri terhadap profitabilitas pada perusahaan Automotive and components yang Go Public di Bursa Efek Indonesia, menyatakan bahwa utang jangka pendek tidak berpengaruh terhadap profitabilitas ${ }^{\mathrm{xii}}$

\section{Pengaruh modal sendiri terhadap profitabilitas}

Uji signifikasi parsial (uji t) menunjukan bahwa nilai signifikasi pada variabel modal sendiri adalah lebih besar daripada tingkat level of significant. Sehingga dapat dikatakan variabel modal sendiri tidak memiliki pengaruh terhadap profitabilitas pada PT. Primarindo Asia Infrastruucture, Tbk selama tahun penelitian. Setiap perusahaan pasti menyukai dana dari dalam perusahaan karena memiliki resiko kesulitan keuangan yang kecil daripada dana dari utang. Namun pada penelitian ini modal sendiri tidak terlalu berpengaruh terhadap profitabilitas dikarenakan perusahaan lebih menyukai menggunakan dana eksternal daripada dana internal yang menyebabkan modal sendiri tidak terlalu berpengaruh pada profitabilitas. Peneliitian ini didukung oleh penelitian sebelumnya, penelitian yang dilakukan oleh Sari (2014) yang meneliti tentang pengaruh penggunaan dana dari luar perusahaan dan modal sendiri terhadap profitabilitas pada perusahaan property and real estate yang terdaftar di BEI menyatakan bahwa modal sendiri tidak berpengaruh signifikan terhadap profitabilitas. ${ }^{\text {xii }}$

\section{Pengaruh liabilitas jangka pendek dan modal sendiri terhadap profitabilitas}

Uji signifikasi (uji F) menunjukan bahwa secara bersama-sama liabilitas jangka pendek dan modal sendiri tidak berpengaruh terhadap profitabilitas, hal ini dapat dilihat dari hasil pengujian secara parsial bahwa kedua variabel tersebut tidak memiliki pengaruh terhadap profitabilitas. Penelitian ini tidak sesuai dengan penelitian sebelumnya, penelitian dari silitonga \& ginting (2019) yang meneliti tentang pengaruh penggunaan dana dari luar perusahaan dan modal sendiri terhadap profitabilitas pada perusahaan property and real estate yang terdaftar di Bursa Efek Indonesia menyatakan bahwa pendanaan dari luar (hutang jangka pendek dan hutang jangka panjang) dan modal sendiri berpengaruh signifikan terhadap profitabilitas. ${ }^{\text {xiv }}$.

\section{Simpulan}

Berdasarkan hasil uji hipotesis dan analisis mengenai pengaruh liabilitas dan ekuitas terhadap profitabilitas pada PT. primarindo Asia Infrastructure Tbk, maka dapat disimpulkan bahwa liabilitas jangka pendek, dan modal sendiri sama-sama tidak berpengaruh terhadap profitabilitas karena perusahaan ini lebih menyukai menggunakan dana dari luar perusahaan berupa hutang dalam jangka waktu yang lama dan menyebabkan resiko yang cukup besar sehingga tidak terlalu berpengaruh terhadap profitabilitas.

\section{Saran}

Rekomendasi yang dapat diberikan beberapa pihak yaitu bagi perusahaan untuk meningkatkan profitabilitas perusahaan harus lebih banyak menggunakan dana dari dalam perusahaan agar dapat mengurangi penggunaan dana dari luar perusahaan yang memilki resiko lebih tinggi. Setiap perusahaan pasti lebih menyukai penggunaan dana yang berasal dari dalam perusahaan karena memiliki resiko yang lebih kecil daripada utang. Penggunaan dana dari modal sendiri ini akan sangat baik dan lebih aman, dana yang didapatkan dari investasi atas modal sendiri sengga baik untuk profitabilitas perusahaan. PT. primarindo Asia Infrastructure Tbk juga harus memperhatikan faktor eksternal lain yang dapat mempengaruhi profitabilitas perusahaan seperti kondisi ekonomi, tingkat suku bunga, dan pajak. 
Footnotes

${ }^{1}$ Prihadi, T, Analisis laporan keuangan: teori dan aplikasi, PPM, Jakarta pusat, 2010 (Prihadi, 2010)

${ }^{2}$ Sudana I.M, Manajemen keuangan perusahaan: Teori dan Praktik, N.I.Sallama, Ed, Erlangga, Jakarta 2015, halaman 181, (Sudana, I.M, 2015, hal, 181)

${ }^{3}$ Irton, Buku pegangan akuntansi, Sekolah tinggi ilmu manajemen YKPN, yogyakarta 2009, (Irton, 2009)

${ }^{4}$ Syamrin, L.M, Pengantar akuntasi: mudah membuat jurnal dengan pendekatan siklus transaksi, PT. Rajagrafindo persada, Depok 2014, (Symarin, 2014)

${ }^{5}$ Rudianto B, Pengantar akuntansi: Konsep dan teknik penulisan laporan keuangan, Erlangga, Jakarta, 2012, hal 47 (Rudianto, 2012)

${ }^{6}$ Sudana I.M, Manajemen keuangan perusahaan: Teori dan Praktik, N.I.Sallama, Ed, Erlangga, Jakarta 2015, halaman 203, (Sudana, I.M, 2015, hal, 203)

7 Rudianto B, Pengantar akuntansi: Konsep dan teknik penulisan laporan keuangan, Erlangga, Jakarta, 2012, hal 277 (Rudianto, 2012, hal 277)

${ }^{8}$ Riyanto, B, Dasar-dasar pembelanjaan perusahaan, cetakan keempat belas, BPFE, yogyakarta 2015, halaman 240 (Riyanto, 2015, hal 240)

${ }^{9}$ Sudana I.M, Manajemen keuangan perusahaan: Teori dan Praktik, N.I.Sallama, Ed, Erlangga, Jakarta 2015, halaman 152, (Sudana, I.M, 2015, hal, 152)

10 Brigham E.F, dan Houston, J.R, Dasar-dasar manajemen keuangan terjemahan Yulianto, A.A, edisi sebelas, Erlangga, Jakarta 2014 (Brigham, 2015)

11 Kasmir, Bank dan lembaga keuangan lainnya, Raja grafindo persada, Jakarta 2008 (Kasmir,2008)

${ }^{12}$ L Ayu,R.2013 analisis pengaruh pendanaan dari kuar perusahaan dan modal sendiri terhadap profitabilitas pada perusahaan Automotive and components yang Go Public di Bursa Efek Indonesia. Jurnal Akutansi AKUNESA vol. 1 no. 2.

13 Sari, S,S. 2014. Pengaruh penggunaan dana dari luar dan modal sendiri terhadap profitabilitas pada perusahaan property and real estate yang terdaftar di BEI. Jurnal akutansi vol. 2 no.1

${ }^{14}$ Silitonga, M, I \& Ginting, C, M. 2019. Prmgaruh penggunaan dana dari luar perusahaan dan modal sendiri terhadap tingkat profitabilitas pada perusahaan property and real estate yang terdaftar di Bursa Efek Indonesia. Jurnal manajemen vol 5 no. 2

\section{Daftar Pustaka}

Brigham, E.F. \& Houston, J.F. 2014. Dasar-dasar Manajemen Keuangan Terjemahan Yulianto, A.A. 2014 (P.A. Ratnaningrum , Ed.) Edisi Sebelas. (Buku 2). Jakarta:erlangga

Irton. 2009. Buku Pegangan Akuntansi. Yogyakarta: Sekolah Tinggi Ilmu Manajemen YKPN.

Kasmir. 2008. Bank Dan Lembaga Keuangan Lainnya. Jakarta: Raja Grafindo Persada.

L Ayu, R. 2013. Analisis pengaruh pendanaan dari luar perusahaan dan modal sendiri terhadap profitabilitas pada perusahaan Automotive and components yang Go Public di Bursa Efek Indonesia. Jurnal akutansi AKUNESA Vol. 1 No. 2

Nadeem, M Et All. 2015. The Effect Leverage On Financial Health Of The Firm: a Study From Cement Industry Of Pakistan. Industrial Engineering Letters Volume 5 (5): 123-126

Prihadi, T. 2010. Analisis Laporan Keuangan : Teori Dan Aplikasi. Jakarta Pusat: PPM. 
Praktito, H., 2019. Pendidikan, Bisnis, Dan Manajemen Menyongsong Era Society 5.0. Cetakan Pertama, Malang:baskara Media.

Riyanto, B. 2015. Dasar-dasar Pembelanjaan Perusahaan. Cetakan Keempat Belas. Yogyakarta: BPFE.

Rudianto, B. 2012. Pengantar Akutansi: Konsep Dan Teknik Penulisan Laporan Keuangan. Jakarta: Erlangga.

Sari,S,S. 2014. Pengaruh pendanaan dari luar perusahaan dan modal sendiri terhadap profitabilitas pada perusahaan property and real estate yang terdaftar di BEI. Jurnal akutansi Vol. 2 No. 1

Syamrin, L.M. 2014. Pengantar Akutansi: Mudah Membuat Jurnal Dengan Pendekatan Siklus Transaksi. Depok: PT. Rajagrafindo Persada

Sudana, I.M. 2015. Manajemen Keuangan Perusahaan: Teori Dan Praktik ( N.I.Sallama, Ed). Jakarta: Erlangga.

Thailab, M.K. 2014. Agency theory, capital structure on profitability of energy american firms. International journal of bussines and management invention volume 3 (12):54-61.

Vatavu, S. 2015. The Impact Of Capital Structure On Financial Performance In Romanian Listed Company. Procedia Economics And Finance, 2015 (32): 1314-1322.

Yani, F.D. 2016. Hutang Jangka Panjang Dan Profitabilitas Di Bank Syariah : Studi Pada PT Bank Muamalat Indonesia. Jurnal Manajemen Strategi Bisnis Dan Kewirausahaan, 2016 10(1): 52-63 
